\title{
MONITORING OF PROGRESSIVE DAMAGE IN BUILDINGS USING LASER SCAN DATA
}

\author{
I. Puente ${ }^{1, *}$, R. Lindenbergh ${ }^{2}$, A. Van Natijne ${ }^{2}$, R. Esposito ${ }^{3}$, R. Schipper ${ }^{3}$ \\ ${ }^{1}$ Defense University Center, Spanish Naval Academy, Plaza de España s/n, 36900, Marín, Spain - ipuente@cud.uvigo.es \\ ${ }^{2}$ Dept. of Geoscience and Remote Sensing, Delft University of Technology, Stevinweg 1, 2628 CN, Delft, The Netherlands - \\ r.c.lindenbergh@tudelft.nl, adriaan@fwrite.org \\ ${ }^{3}$ Dept. of Material, Mechanics, Management and Design, Delft University of Technology, Stevinweg 1, 2628 CN, Delft, The \\ Netherlands - r.esposito@tudelft.nl,h.r.schipper@tudelft.nl
}

Commission II, WG II/10

KEY WORDS: Change, monitoring, unreinforced masonry building, LiDAR, point cloud, post-disaster

\begin{abstract}
:
Vulnerability of buildings to natural and man-induced hazards has become a main concern for our society. Ensuring their serviceability, safety and sustainability is of vital importance and the main reason for setting up monitoring systems to detect damages at an early stage. In this work, a method is presented for detecting changes from laser scan data, where no registration between different epochs is needed. To show the potential of the method, a case study of a laboratory test carried out at the Stevin laboratory of Delft University of Technology was selected. The case study was a quasi-static cyclic pushover test on a two-story high unreinforced masonry structure designed to simulate damage evolution caused by cyclic loading. During the various phases, we analysed the behaviour of the masonry walls by monitoring the deformation of each masonry unit. First a plane is fitted to the selected wall point cloud, consisting of one single terrestrial laser scan, using Principal Component Analysis (PCA). Second, the segmentation of individual elements is performed. Then deformations with respect to this plane model, for each epoch and specific element, are determined by computing their corresponding rotation and cloud-to-plane distances. The validation of the changes detected within this approach is done by comparison with traditional deformation analysis based on co-registered TLS point clouds between two or more epochs of building measurements. Initial results show that the sketched methodology is indeed able to detect changes at the mm level while avoiding $3 \mathrm{D}$ point cloud registration, which is a main issue in computer vision and remote sensing.
\end{abstract}

\section{INTRODUCTION}

Building inspection and maintenance services need to be optimized. Sometimes, the extraction of a geometric property involves a large number of manual, subjective and timeconsuming consecutive measurements which may lead to erroneous assessment of the state of the infrastructure. On other occasions, building managers conduct their geometry studies based on classical geodetic methods, which, despite their high accuracy and precision, allow only a small sample of points to be measured.

In this regard, the use of terrestrial Light Detection and Ranging (LiDAR) for structural monitoring and damage detection has increased significantly in recent years. Due to its capacity to provide fast, dense and accurate measurements, there are several applications in tunnels (Lindenbergh et al., 2009), bridges (Riveiro et al., 2013; Valença et al., 2017), landslides (Abellán et al., 2014; Monserrat and Crosetto, 2008) or breakwaters (Puente et al., 2014). Change detection from laser scan data is normally performed by comparing the $3 \mathrm{D}$ coordinates of corresponding points of two or more epochs (Lindenbergh and Pfeifer, 2005; Lindenbergh and Pietrzyk, 2015; Van Gosliga et al., 2006). However, with this approach the registration of different sets of data into one coordinate system is necessary. For more critical applications, when the expected result is very close to the noise level of individual laser scanner observations, tiny registration errors may lead to erroneous results when detecting changes (Shen et al., 2017).

In this paper, we propose an alternative approach to detect changes where no registration between different epochs is needed. To show the potential of the method, a case study of a quasi-static cyclic pushover lab test on a two-story high unreinforced masonry structure was selected. The building had calcium silicate (CS) element masonry walls and reinforced concrete slabs. The test was designed to simulate the damage evolution of the building caused by seismic loading. During the various phases, we analyzed the behaviour of the masonry wall by monitoring the deformation of each element. We evaluate the individual element rotations and the residuals of the points on each of the elements with respect to the main wall, where a plane is previously fitted using PCA. This paper is organized as follows. Sections $2 \& 3$ present the experiment description and the framework of our proposed methodology while the experimental results and their analysis are provided in Section 4. Finally, Section 5 summarizes the main points of our study and looks into future work.

\section{CASE STUDY AND MEASUREMENT SETUP}

In this paper we propose a method to evaluate the damage evolution in buildings. This method can serve as a powerful tool within the inspection and monitoring of existing buildings.

To validate the method, we selected the case study of a quasistatic cyclic pushover test on an unreinforced masonry structure designed to simulate the damage evolution caused by seismic loading (Esposito et al., 2018). The test was carried out at the Stevin II laboratory of Delft University of Technology.

The building was a two-story high structure having walls made of calcium silicate (CS) element masonry and reinforced concrete slabs as floors. The structure had a floor plan of $5.4 \mathrm{x}$ $5.2 \mathrm{~m}$ and a total height of $5.4 \mathrm{~m}$ (Figure 1). The south and

\footnotetext{
* Corresponding author
} 
north facades, which are identical, are represented only by the two piers connected to the transversal walls. Two sizes of the piers have been selected: on the western side the wide piers P1 and $\mathrm{P} 3$ have a width of $1.1 \mathrm{~m}$, while on the eastern side the narrow piers $\mathrm{P} 2$ and $\mathrm{P} 4$ have a width of $0.6 \mathrm{~m}$. Large masonry elements having dimensions $897 \times 643 \times 100-\mathrm{mm}$ were used for the facade piers, while units having dimensions $897 \times 643 \times 120$ $\mathrm{mm}$ were used for the transversal wall.

The structure was loaded by four actuators, two per floor, positioned on the west side. A displacement was cyclically imposed at the second floor level, while a ratio of 1:1 was maintained between the forces at the two floor levels $(\mathrm{F} 1+\mathrm{F} 3=$ F2 + F4). The applied displacement induced the piers on the north and south façade to deform in-plane, and the transversal wall to deform out-of-plane. The test was carried out in five phases named: Initial, Pre-peak, Peak, Post-peak I, Post-peak II.
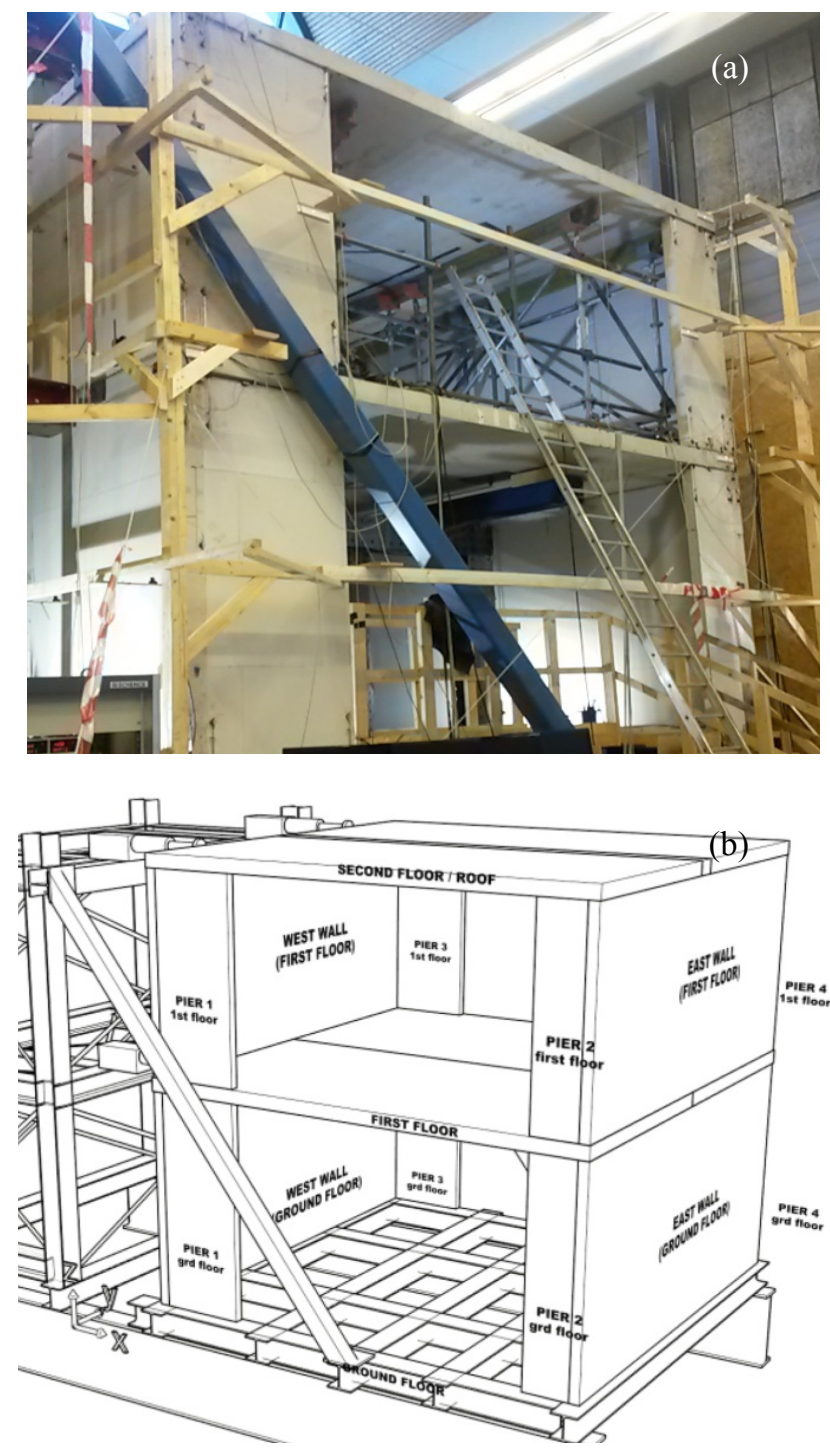

Figure 1. The structure: (a) Photo and (b) Schematic 3D view with building walls and piers.

Laser scanning was used to acquire repeated three-dimensional point clouds of the structure after each testing phase was concluded (see Table 1). This allowed the identification of the locations and geometry of the masonry elements but also the measurement of the permanent deformations of the structure.

\begin{tabular}{|l|l|c|}
\hline Abbr. & Test name & Data \\
\hline $\mathrm{E}_{0}$ & Initial (before test) & $15 / 02 / 2017$ \\
$\mathrm{E}_{\mathrm{I}}$ & Peak & $03 / 03 / 2017$ \\
$\mathrm{E}_{\mathrm{II}}$ & Post-peak I & $08 / 03 / 2017$ \\
$\mathrm{E}_{\mathrm{III}}$ & Post-peak II & $30 / 03 / 2017$ \\
\hline
\end{tabular}

Table 1. Summary of epochs of TLS data

A ScanStation C10 scanner was used during the experiment (Figure 2). This is a TOF scanner with an effective range of 300 $\mathrm{m}$ at $90 \%$ reflectivity. The accuracy of range measurements is 6 and $4 \mathrm{~mm}$ (1 sigma) (in position and depth, respectively) at ranges up to $50 \mathrm{~m}$ (Geosystems, 2012). The location of the laser stations was planned to minimize possible occlusions. A total of 40 scans was recorded during the four epochs.

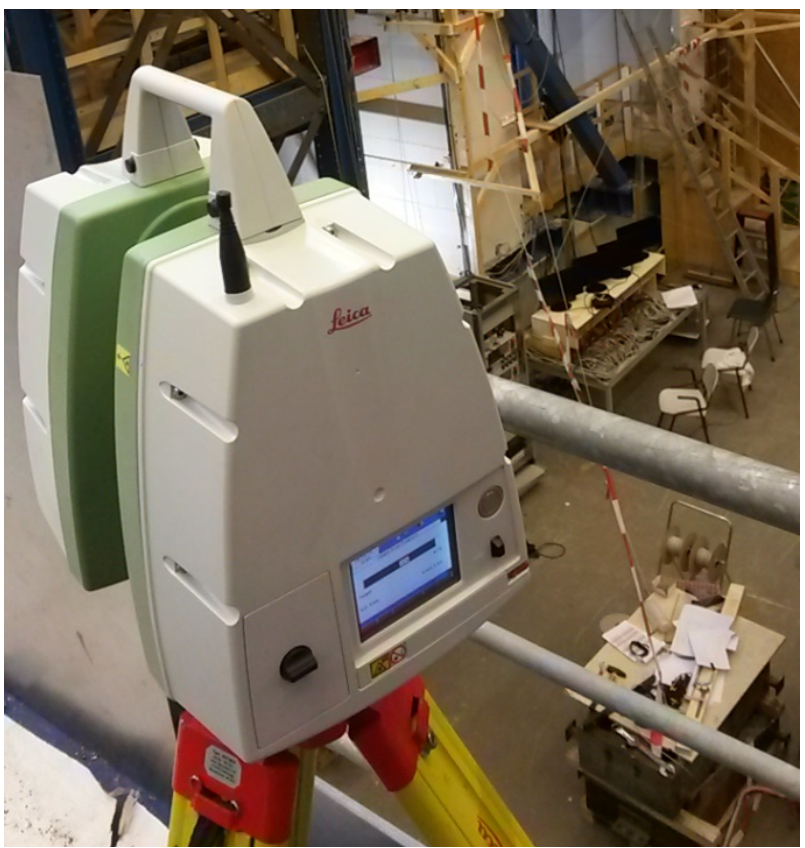

Figure 2. Leica ScanStation C10 used during field data collection.

For the sake of simplicity, we consider here only the change monitoring of the west wall and wide pier 3 at the ground floor, which are the most damaged parts of the structure during the test. (Figure 3). However, the method could be applied in the same way to the rest of the structure.

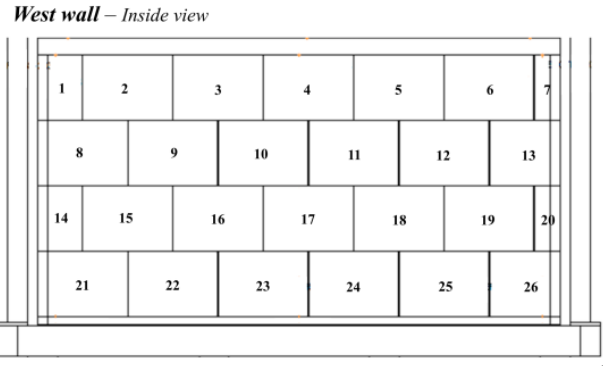

(a)

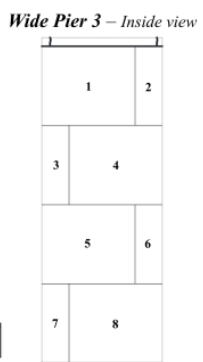

(b)
Figure 3. Enumeration of individual elements using a view from inside the building: (a) 26 elements in west wall and (b) 8 elements in wide pier 3. 
Before the method for this purpose is designed, two facts should be pointed out: (1) wide pier 3 collapsed before Post-Peak II and therefore, there is no TLS data available for that last epoch; (2) Initial TLS point clouds are located in a local coordinate system (Figure 4). To facilitate the interpretation of the deformation monitoring, we define the coordinate system as shown in Figure 1: The $\mathrm{X}$ axis is perpendicular to the west and east walls, $\mathrm{Y}$ axis is perpendicular to the piers while the $\mathrm{Z}$ axis is pointing upwards. The origin of coordinates is set at the ground floor corner of the west wall and the wide pier 3 (Figure 9).

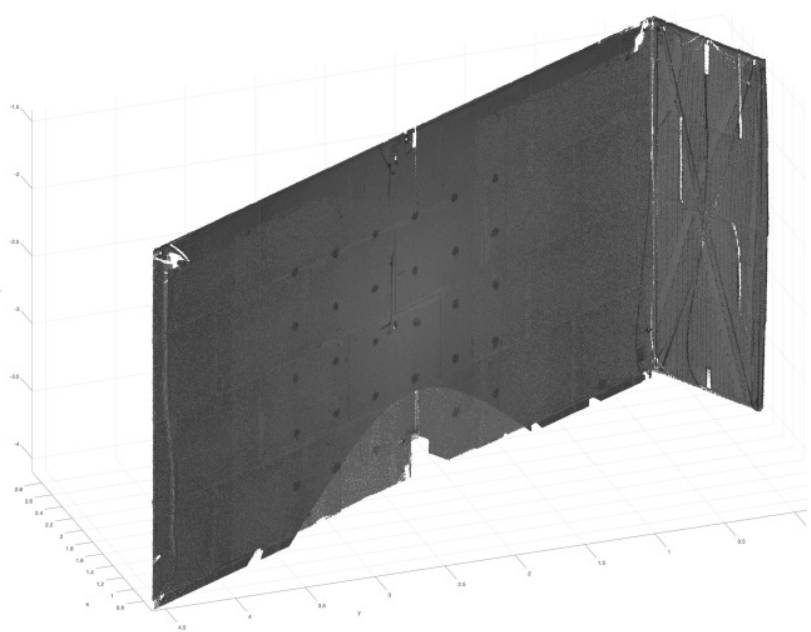

Figure 4. Initial 3D point cloud of west wall and wide pier 3 (ground floor) after data registration of Post-peak I epoch. Data registration is only used for validation purposes.

\section{METHODOLOGY}

The algorithm overview summarizes the steps performed to detect deformations and rotations, as shown in Figure 5. The new approach (1) is then compared with the co-registered approach (2), used for validation purposes.

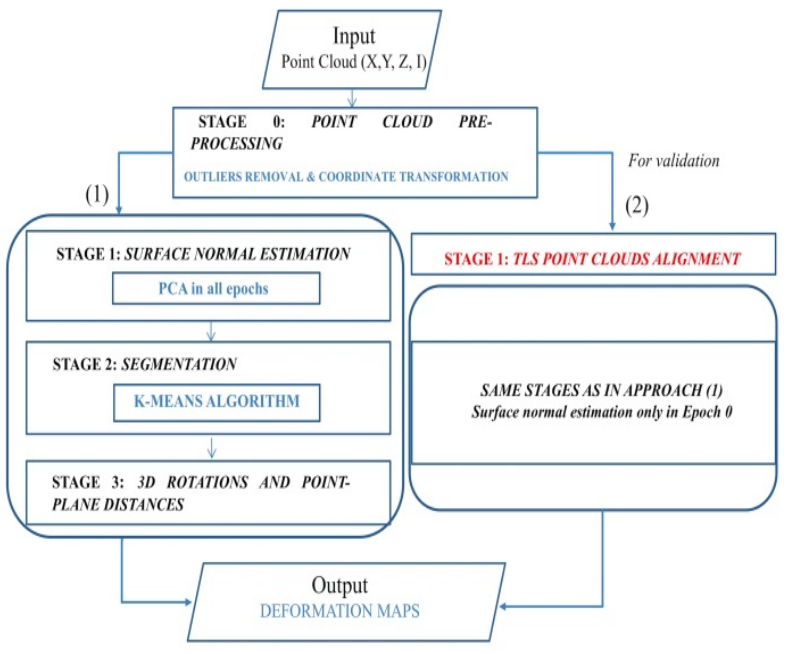

Figure 5. Algorithm overview

To implement the proposed approach, we need to remove noise, outliers and irrelevant points from the 3D point clouds obtained in each of the epochs collected. Considering that the building was scanned with a scaffolding structure all around, some manual editing was required to clean the data. As mentioned, the point clouds of both walls were rotated and translated in such a way that their points aligned to the longitudinal axes of the 3D space. Afterwards, three steps are performed: (1) Plane fitting using PCA; (2) Segmentation of individual elements; (3) Estimating rotations and cloud-to-plane distances of each constituent element vs. wall. These steps will enable us to detect the abovementioned changes.

\subsection{Plane fitting}

Given a set of $3 \mathrm{D}$ points, we want to find a plane (i.e., unit normal $n$ and center $q$ ) that describes this set of points. This plane is determined using Principal Component Analysis (PCA). PCA minimizes the perpendicular distances from the data to the fitted model. The coefficients for the first two principal components define vectors that span the plane; the third principal component, normal to the first two and oriented outwards, is then the eigenvector associated with the smallest eigenvalue of the symmetric positive semidefinite variancecovariance matrix of the neighboring data points (Castillo and Zhao, 2009).

The fitted plane approximately minimizes the sum of the squared errors. These squared errors or residuals are the perpendicular distances between the original data minus the fitted points.

The plane equation of the wall is expressed as:

$$
n_{x} q_{x}+n_{y} q_{y}+n_{z} q_{z}+d=0
$$

where:

$$
\begin{aligned}
& \mathrm{n}=\left(n_{x}, n_{y}, n_{z}\right) \\
& \mathrm{q}=\left(q_{x}, q_{y}, q_{z}\right)
\end{aligned}
$$

\subsection{Segmentation of individual elements}

In this section, we use the intensity information provided by the laser scanner to segment the different CS elements using a Kmeans clustering algorithm as proposed by Shen et. al., 2017.

\subsection{Estimating rotations and signed cloud-to-plane distances}

In order to parameterize the location of CS elements in 3D space, a plane model is again fitted to each individual element, defined by a normal and its center. For estimating the rotations, the normal vectors of the elements are computed. We use the same local coordinate system defined in Section 2, where coordinates $\mathrm{X}, \mathrm{Y}$ correspond to the length or width of the elements, depending on the wall selected and $\mathrm{Z}$ to their heights. The resulting angles are computed as the dot product between each element normal unit vector $\mathrm{n}$ and the corresponding fixed axis $(\mathrm{u}, \mathrm{v})$ of the wall following the right-hand rule. Monitoring the rotations can be easily achieved by looking at those angles and comparing them with the fixed coordinate system.

Lastly, we also compute the signed point-plane distances between the plane $(n, q)$ fitted to the main wall and data points $p_{i}$ of each of the individual elements. This is a classical way to detect changes, where the distances are computed orthogonally to the main wall. We evaluate the mean value of those distances and the standard deviation. For the interpretation, it should be taken into consideration that having a mean distance of around 0 does not mean there is no displacement, because signed distances can be compensated. 


\section{RESULTS AND DISCUSSION}

\subsection{Deformation analysis}

To simplify the interpretation of the approach, only elements with larger changes have been considered in the methodology. As an example, for the wide pier 3 the chosen CS elements are: $1,4,6$ and 8 . For the west wall, the attention has been put on the outer elements.

Figure 6 shows the results of the signed point-plane distances of the abovementioned elements vs. the parametric plane model of the entire wall data recorded after Post-Peak I phase $\left(E_{I I}\right)$. Therefore, deformation values at this point are relative (and not absolute) to that best fitting plane of a 3D wall point cloud computed with PCA, being positive if points are on the same side of the plane as the normal vector $n$ and negative if they are on the opposite side. In other words, positive deformations along the $\mathrm{Y}$ axis are then from the inside to the outside of the building.

The process was repeated for the remaining epochs, each one defined by its plane model. Full deformation data of wide pier 3 are summarized in Table 2.

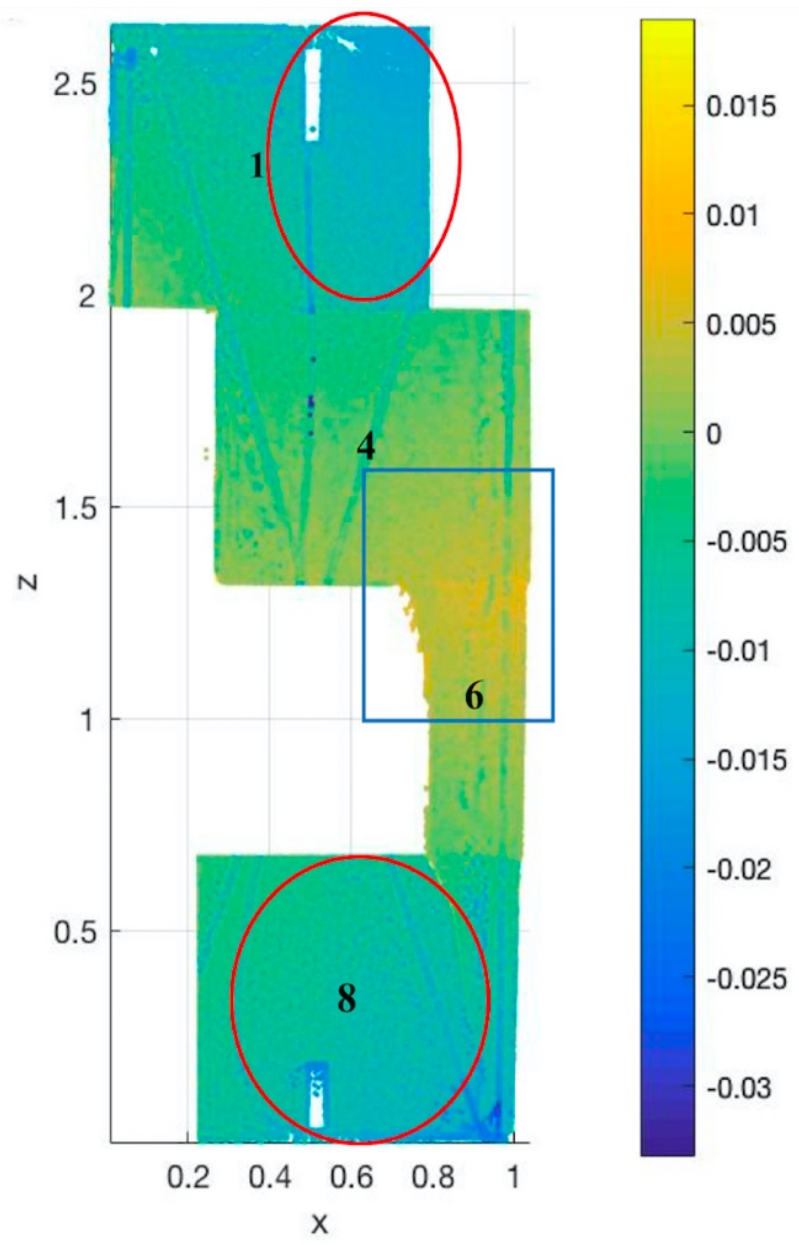

Figure 6. Deformation map along the $\mathrm{Y}$ axis (units in meters) for CS elements 1, 4, 6 and 8 of wide pier 3 after Post-Peak I

$\left(\mathrm{E}_{\mathrm{II}}\right)$.

\begin{tabular}{|c|c|c|c|}
\hline Epoch & Element & $\begin{array}{c}\text { Mean distance } \\
(\mathrm{mm})\end{array}$ & STD (mm) \\
\hline \multirow{3}{*}{$\mathrm{E}_{0}$} & Elem. 1 & -1.5 & 2.1 \\
& Elem. 4 & 1.1 & 2.0 \\
& Elem. 6 & 2.7 & 2.2 \\
& Elem. 8 & -1.3 & 2.2 \\
\hline \multirow{3}{*}{$\mathrm{E}_{\mathrm{I}}$} & Elem. 1 & -1.4 & 2.4 \\
& Elem. 4 & 1.2 & 2.3 \\
& Elem. 6 & 2.6 & 2.5 \\
& Elem. 8 & -1.6 & 2.4 \\
\hline \multirow{3}{*}{$\mathrm{E}_{\mathrm{II}}$} & Elem. 1 & -4.0 & 4.2 \\
& Elem. 4 & 3.4 & 3.2 \\
& Elem. 6 & 6.1 & 3.0 \\
& Elem. 8 & -3.4 & 3.2 \\
\hline
\end{tabular}

Table 2. Summary of out-of-plane deformations for CS elements 1, 4, 6 and 8 of wide pier 3 .

Taking this into account, we have detected negative out-ofplane displacements in elements 1 and 8 (red highlighted) and positive deformations in the contact between elements 4 and 6 (blue highlighted). This phenomenon was observed in all epochs, with their mean distances and standard deviations increasing slightly over time (see Table 2).

Moreover, it is possible to compute the angle between each element with respect to the parametric plane model. Those angles are in all epochs less than 1 degree. As a consequence, we assume that the elements are still parallel to the plane model. The evidence is given on the following Figure 7, which also proves the out-of-plane displacement for element 8 in pier 3 .

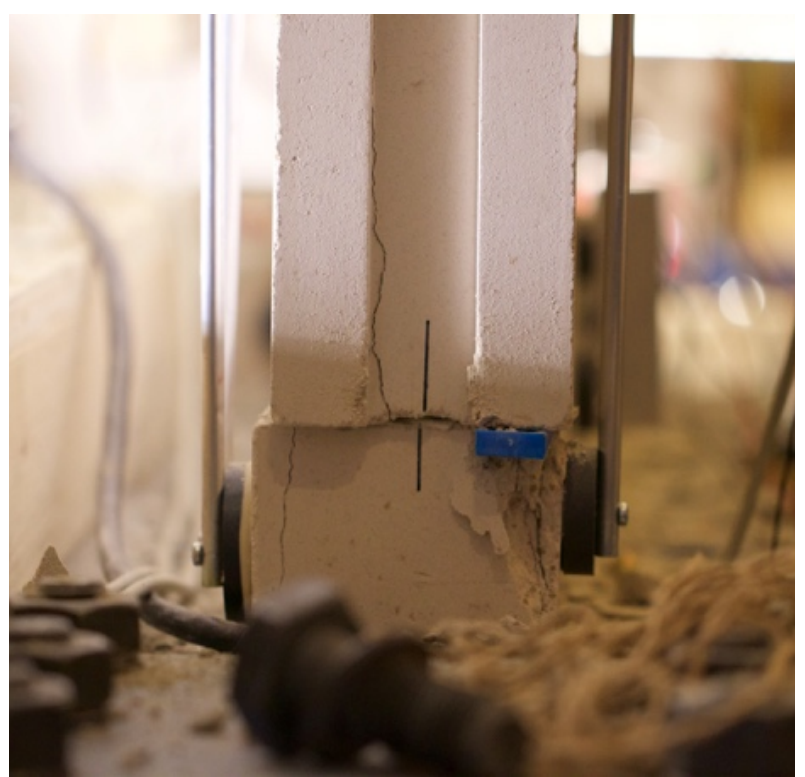

Figure 7. Out-of-plane displacement of element 8 in wide pier 3.

Regarding the west wall data, deformations along the $\mathrm{X}$ axis are clearly visible at the outer sides of this wall after Post-peak II (E $\left.\mathrm{E}_{\mathrm{III}}\right)$. 
In fact, CS elements placed on the left side, namely $1,2,8,14$ and 21 show the largest mean distances: 46, 13, 33, 46 and 20 $\mathrm{mm}$ in the negative direction of the abovementioned axis, as displayed on Figure 8.

(a)

(b)

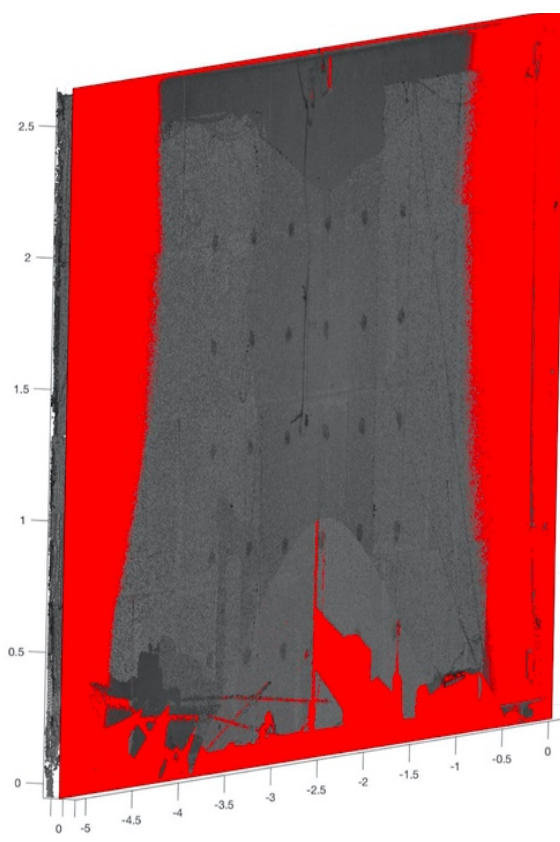

P3

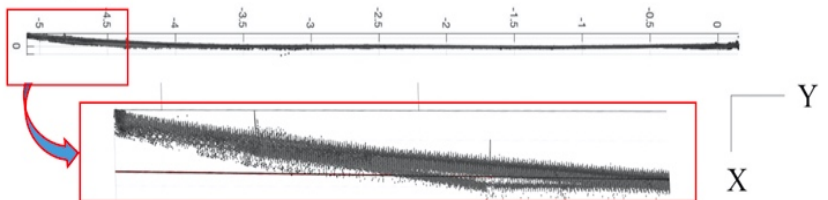

Figure 8. West wall point cloud: (a) Fitted plane to Post-Peak II data. (b) Top view showing the deformations along the $\mathrm{X}$ axis.

Moreover, rotations in these elements are more significant than for wide pier 3 , varying in a range of $3.6^{\circ}$ (element 1 ) to $6.1^{\circ}$ (element 14). Elements on the right side (near pier 3 ) also have negative displacements, but to a lesser extent.

The extensive out-of-plane deformation of the west wall at the side of pier 1 was a direct consequence of the damage in the pier; fragments of CS elements fell between the pier and the wall creating a wedge effect that lead to local deformation of the wall. Lastly, those elements placed in the central part of the wall or adjacent to the outer elements show deformations, either in the positive direction of the $\mathrm{X}$ axis or very close to zero. This pattern is repeated in the previous epoch recorded $\left(\mathrm{E}_{\mathrm{II}}\right)$, though the deformations are smaller. In the first two epochs, no significant displacements are detected.

\subsection{Validation with co-registered TLS point clouds}

The point cloud alignment is performed by the Leica Cyclone software, using ground control points to improve the overall accuracy. The registration error shown as its mean absolute is $0.002 \mathrm{~m}$, which is considered good. Subsequently, each point cloud was reoriented following the coordinate system defined in Section 2 (Figure 9).

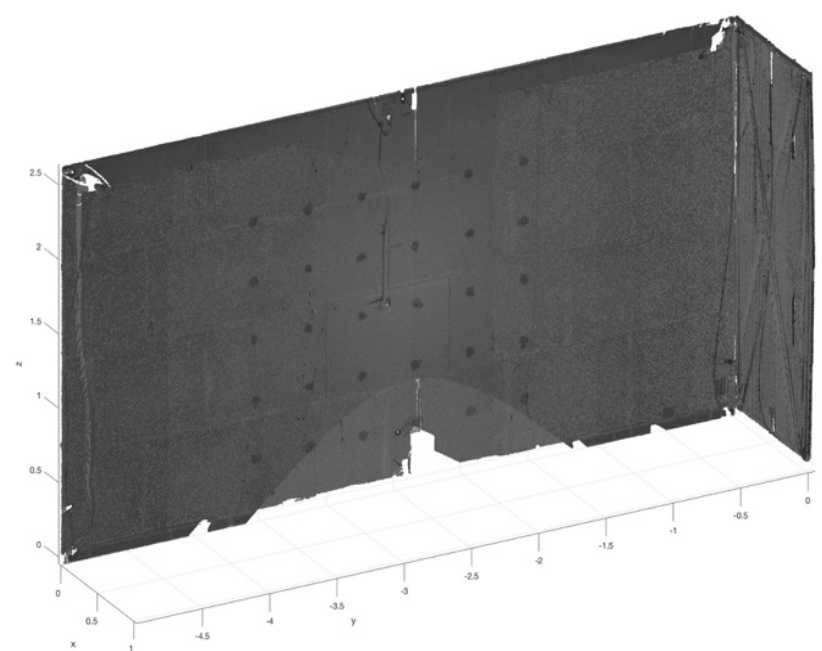

Figure 9. Rotated 3D point cloud of west wall and wide pier 3 (ground floor) after data registration of Post-peak I epoch. Walls are now aligned with the three coordinate axes.

In order to detect absolute changes in both cases, it was necessary to study the geometry of wide pier 3 and the west wall from Epoch $\mathrm{E}_{0}$ (before any pushover test was carried out) to $\mathrm{E}_{\mathrm{II}}$ (after Post-peak I phase) and $\mathrm{E}_{\mathrm{III}}$ (after Post-Peak II phase), respectively.

Particularly, the signed distances between each point forming the different point clouds and the best fitting planes of pier 3 and the west wall in Epoch $\mathrm{E}_{0}$ (reference datasets) were computed. For comparison, the deformation map along the $\mathrm{X}$ axis of the west wall after $\mathrm{E}_{\mathrm{III}}$ is represented in Figure 10. Similarly, the deformation map along the $\mathrm{Y}$ axis of wide pier 3 after $E_{\text {II }}$ is plotted (Figure 11) together with the Table 3 containing the numeric results for the selected CS elements.

\begin{tabular}{|c|c|c|c|}
\hline Epoch & Element & $\begin{array}{c}\text { Mean distance } \\
(\mathrm{mm})\end{array}$ & STD (mm) \\
\hline \multirow{3}{*}{$\mathrm{E}_{0}$} & Elem. 1 & -1.5 & 2.1 \\
& Elem. 4 & 1.1 & 2.0 \\
& Elem. 6 & 2.7 & 2.2 \\
& Elem. 8 & -1.3 & 2.2 \\
\hline \multirow{3}{*}{$\mathrm{E}_{\mathrm{I}}$} & Elem. 1 & 0.8 & 2.4 \\
& Elem. 4 & 3.8 & 2.3 \\
& Elem. 6 & 5.7 & 2.5 \\
& Elem. 8 & 1.9 & 2.3 \\
\hline \multirow{3}{*}{$\mathrm{E}_{\mathrm{II}}$} & Elem. 1 & -2.5 & 3.7 \\
& Elem. 4 & 7.0 & 3.8 \\
& Elem. 6 & 11.8 & 2.9 \\
& Elem. 8 & 1.8 & 2.9 \\
\hline
\end{tabular}

Table 3. Summary of deformations for CS elements $1,4,6$ and 8 of wide pier 3 with respect to the plane model of Epoch 0 . 


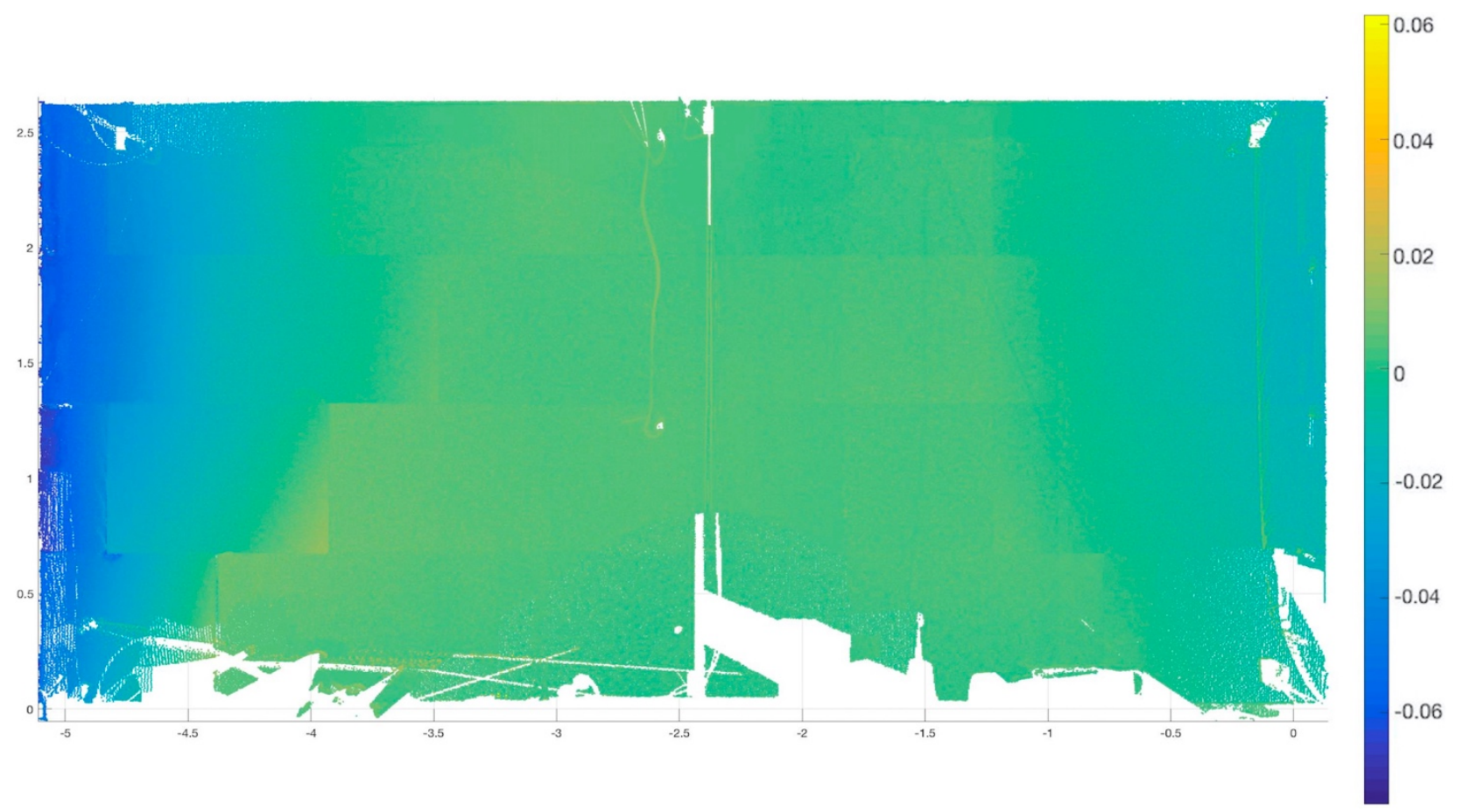

Figure 10. Front view of west wall after Post-Peak II. Blueish colors represent negative deformations along the $\mathrm{X}$ axis (from inside the building to outside) versus a reference plane computed using PCA on the first epoch. Units are in meters.

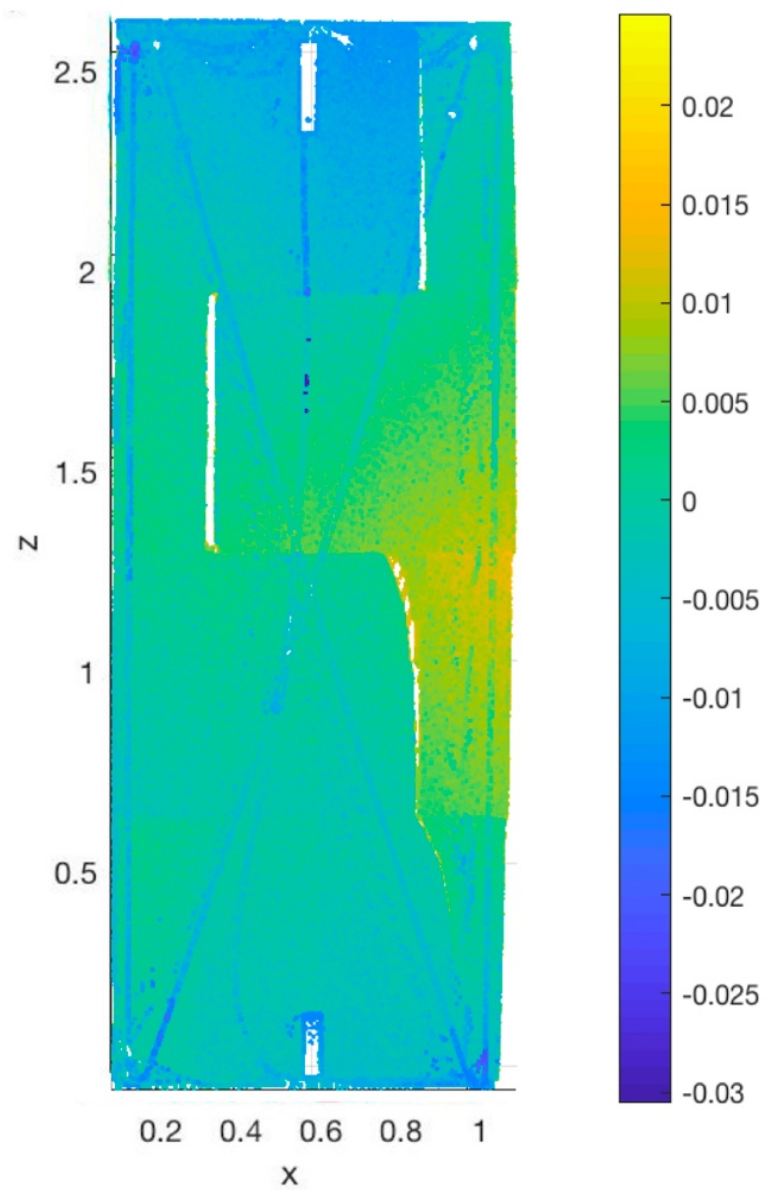

Figure 11. Deformation map along the $\mathrm{Y}$ axis (units in meters) for the entire wide pier 3 after Post-Peak I $\left(\mathrm{E}_{\mathrm{II}}\right)$. Epoch $0\left(\mathrm{E}_{0}\right)$ was used as a reference to parameterize the plane model.
The same patterns are again observed in both deformations maps with regards to the previous ones, which in turn demonstrates the feasibility of the proposed approach. However, deformation values are not exactly the same because Figures 6 and 8 show relative measurements while Figures 10 and 11 show the absolute ones with respect to the reference dataset $\left(\mathrm{E}_{0}\right)$. Moreover, Figures 10 and 11 might include the effect of the registration error, influencing the result of the mean distance value when is very close to its noise level (see for example, elements 1 and 8 in Table 3).

\section{CONCLUSIONS}

In this paper a new method has been presented that identifies deformations in buildings from repeated laser scanning data, and where no registration between the different epochs is necessary. This method was demonstrated on two unreinforced masonry walls of a structure subject to cyclic loading and located at the TU Delft Stevin laboratory. Both walls were scanned before and after each testing phase which caused recognizable damage. The algorithm allows to first fit a plane to the wall data in each epoch and then computes the rotations and translations of each CS element (after their segmentation into planar segments). A suitable coordinate system with axes parallel and perpendicular to the walls under study was designed to facilitate the interpretation of the results.

The method was adopted to detect out-of-plane deformations of pier 3 and the west wall. Although the load was imposed such that pier 3 could deform only within its plane, substantial outof-plane deformation could be detected. Due to previous damage, the pier-to-floor connections were both cracked giving the freedom to the pier to move in the 3D space (similar to a washing machine). The load imposed at floor level induced outof-plane deformations in the west wall. The method was able to detect the non-uniformity of the out-of-plane deformation 
resulting from the substantial damage occurred in the adjacent piers.

As future work, it would be of interest to investigate the registration methods implemented in the Leica processing software, in order to know the accuracy of the scans registration used to build the complete walls in each epoch. The scan point error varies also with the range, intensity and incidence angle, therefore these parameters should be studied to see how relevant they are in the measurement of these deformations. Lastly, the cracks that appeared in wide pier 3 are not automatically detected and monitored, so they should also be studied in the future.

\section{ACKNOWLEDGEMENTS}

Authors want to give thanks to the Ministry of Education, Culture and Sport (Spain) for the financial support given through human resources José Castillejo grant CAS17/00473.

The pushover test was carried out as part of an extensive research project funded by NAM under contract numbers UI63654 "Testing program 2016 for Structural Upgrading of URM Structures", which is gratefully acknowledged. The masonry material was made available by the calcium silicate masonry association VNK, which is thankful acknowledged.

\section{REFERENCES}

Abellán, A., Oppikofer, T., Jaboyedoff, M., Rosser, N. J., Lim, M., Lato, M. J., 2014. Terrestrial laser scanning of rock slope instabilities. Earth Surface Processes and Landforms, 39(1), pp. 80-97.

Castillo, E. and Zhao, H., 2009. Point cloud segmentation via constrained non linear least squares surface normal estimates, Recent UCLA Computational and Applied Mathematics Reports.

Geosystems, L. Leica ScanStation C10; Product specifications: Heerbrugg, Switzerland, 2012.

Esposito, R., Jafari, S., Ravenshorst, G.J.P., Schipper, H.R. and Rots, J.G., 2018. Influence of the behaviour of calcium silicate brick and element masonry on the lateral capacity of structures. In: Australasian Masonry Conference, Sydney, Australia.

Lindenbergh, R., Pfeifer, N., 2005 A statistical deformation analysis of two epochs of terrestrial laser data of a lock. In: Proceedings of the $7^{\text {th }}$ Conference on Optical 3D Measurement, Vienna, Austria. pp. 61-70.

Lindenbergh, R., Pietryzk, P., 2015. Change detection and deformation analysis using static and mobile laser scanning. Applied Geomatics, 7, pp. 65-74.

Lindenbergh, R., Uchanski, L., Bucksch, A., Van Gosliga, R., 2009. Structural monitoring of tunnels using terrestrial laser scanning. Reports on Geodesy, 2, pp. 231-238.

Monserrat, O. and Crosetto, M., 2008. Deformation measurement using terrestrial laser scanning data and least squares 3D surface matching. ISPRS Journal of Photogrammetry and Remote Sensing, 63(1), pp.142-154.

Puente, I., Lindenbergh, R., González-Jorge, H., Arias, P., 2014. Terrestrial laser scanning for geometry extraction and change monitoring of rubble mound breakwaters. In: The International Annals of the Photogrammetry, Remote Sensing and Spatial Information Sciences, Riva del Garda, Italy, Vol. II- 5, pp. 289-
295.

Riveiro, B., González-Jorge, H., Varela, M., Jauregui, D.V., 2013. Validation of terrestrial laser scanning and photogrammetry techniques for the measurement of vertical underclearance and beam geometry in structural inspection of bridges. Measurement, 46(1), pp. 784-94.

Shen, Y., Lindenbergh, R., Wang, J., 2017. Change analysis in structural laser scanning point clouds: The baseline method. Sensors, 17(1), pp. 26.

Valença, J., Puente, I., Júlio, E., González-Jorge, H., AriasSánchez, P., 2017. Assessment of cracks on concrete bridges using image processing supported by laser scanning survey. Construction and Building Materials, 146, pp. 668-678.

Van Gosliga, R., Lindenbergh, R., Pfeifer, N., 2006. Deformation analysis of a bored tunnel by means of terrestrial laser scanning. 2009. In: The International Archives of the Photogrammetry, Remote Sensing and Spatial Information Sciences, Dresden, Germany, Vol. XXXVI, Part 5, pp. 167-172. 